\title{
Estrogenic Activity of Ethanolic Extract of Papaya Peels (Carica Papaya L.) on Uterine Weight And Mammae Gland Proliferation on Ovariectomy Rats
}

\author{
Dhania Novitasari $^{1}$, Devyanto Hadi Triutomo ${ }^{1}$, Fitriana Hayyu Arifah ${ }^{1}$, Anselma Ivanawati ${ }^{1}$, \\ Zahrotul Ulum ${ }^{1}$, Retno Murwanti ${ }^{1,2, *}$ \\ ${ }^{1}$ Cancer Chemoprevention Research Centre, Faculty of Pharmacy, Universitas Gadjah Mada, \\ Yogyakarta, Indonesia \\ ${ }^{2}$ Pharmacology and Clinical Pharmacy Department, Faculty of Pharmacy, Universitas Gadjah Mada, Yogyakarta, Indonesia
}

\begin{abstract}
Papaya bark is one of Indonesia's natural wealth that contains flavonoid compounds such as myricetin and kaempferol that included in the phytoestrogen compounds. The aim of this study is to examine the estrogenic effects of ethanolic extract of papaya peels (EEPP) on the development of mammae gland and the increasing of uterine weight. The in vivo test was performed in ovariectomized Sprague Dawley female rats. After 30 days of treatment, animals were sacrificed to take the uterus and mammae glands. Measurement of uterine weight and mammae gland was observed by hematoxylin-eosin staining method to know the lobulus development and AgNOR staining to determine the proliferation level of mammae gland epithelial cells. The results showed that EEPP at the concentrations of 500 and $1000 \mathrm{mg} / \mathrm{kgBW}$ were able to increase uterine weight and proliferation of mammae gland. In conclusion, papaya bark has the potential as phytoestrogen compound to maintain female reproductive health and woman beauty.
\end{abstract}

Keywords : Ethanolic extract of papaya peels (EEPP), phytoestrogen, ovariectomized rats, uterine weight, mammae proliferation

\section{INTRODUCTION}

Post menstrual or menopause is a natural process that will be experienced by every woman that marked by a significant decrease in estrogen hormone. The estrogen hormone is known to be responsible for secondary development in women's bodies such as breast and uterus (Frasor, et al., 2003). Deficiency in estrogen can lead to discomfort and decrease in the quality of life of women such as hot flashes, insomnia, sexual dysfunction, vaginal dryness, cardiovascular disease, and bone loss
(Mendelsohn and Karas, 2010). The discomfort can be overcome by giving estrogen from outside the body known as Hormone Replacement Therapy (HRT). However, long-term use of HRT has many side effects and increases the incidence of breast cancer (Chlebowski, et al., 2009). Therefore, a safe

Submitted: May 23, 2018

Revised: June 7, 2018

Accepted: June 30, 2018

*Corresponding author: retno_murwanti@ugm.ac.id 
potential alternative treatment is needed, one of them is by using phytoestrogens. Phytoestrogens are chemical compounds in plants that have estrogenic activity that can replace the function of estrogen (Yildiz, 2005).

One of the natural ingredients in Indonesia that reported to have phytoestrogen content is papaya peels (Carica papaya L.) which in everyday is still rarely used. The compounds contained in the peels of papaya are myricetin and kaempferol that belong to the flavonoid group (Rivera-Pastrana, et al., 2010). Myricetin and kaempferol have been shown to have an estrogenic effect on in vitro assays (Maggiolini, et al., 2005, Oh, et al., 2006) and in vivo tests according to Pratama, et al. (2011) and Trivedi, et al. (2008).

This study aims to determine the interaction of flavonoid myricetin and kaempferol compounds contained in EEPP to estrogen receptor through molecular docking. Then became the basic of in vivo testing to determine the effects of EEPP on the development of ovariectomized Sprague Dawley rat female mamme gland. The results of this study are expected to be the basic in solving the problem of beauty and reproductive health in menopausal women.

The aim of this study is to investigate the estrogenic effect of papaya peels on uterine weight and proliferation of mammae gland in ovariectomized Sprague Dawley female rats.

\section{MATERIALS AND METHODS}

\section{Tools and Materials}

Papaya peels obtained from Wedomartani, Sleman, Yogyakarta, Indonesia. $70 \%$ ethanol (Merck), ketamine $100 \mathrm{mg} / \mathrm{mL}$, plain catgut sutures 3/0 Meiyi®, $\mathrm{NaCl}$ 0.9\% (PT Otsuka, Jakarta), Enbatic ${ }^{\circledR}$ antibiotic (PT Erela, Semarang), Betadin ${ }^{\circledR}$ (PT Mahakam Beta Farma, Jakarta), CMC-Na (E.Merck), aquades, 10\% formalin (Asia lab.), Estradiol (Sigma), Haematoxylin-Eosin staining reagents and AgNOR.

\section{Extraction of Papaya Peels}

Papaya peels obtained from Wedomartani, Sleman. Accumulated papaya peels is dried with oven, then made powder using blender and extracted with $70 \%$ ethanol (maceration). The obtained maserate was concentrated using a rotary evaporator into a viscous extract.

\section{in vivo Assay}

Thirty five of Sprague Dawley female rats were placed in a plastic cage with husk pads and fed with pellets and given drink of PDAM water (ad libitum). The extract was given in the form of a suspension in a $0.5 \%$ CMC-Na solution. The extract solution was made freshly before it was administered to the test animals. Rats were divided into seven treatment groups with 5 rats per group: Group I: non-ovariectomized base line (NOVX), Group II: ovariectomy base line (OVX), Group III: ovariectomy control, Group IV: $0.5 \% \mathrm{CMC}-\mathrm{Na}$ treatment (control negative), Group V: treatment of estradiol $2 \mu \mathrm{g} /$ day, Group VI: treatment of EEPP concentration of $500 \mathrm{mg} / \mathrm{kgBW}$, Group VII: treatment of EEPP concentration of $1000 \mathrm{mg} /$ $\mathrm{kgBW}$. Group II to VII were excised at age 70 days. For group I, rats were conditioned as if they were ovariectomized. The experiment was carried out for 1 month, at the end of the experiment all rats uterine were taken and mammae glands to be analyzed.

\section{Determination of Uterine Weight}

Wet uterine samples are taken at the end of the treatment period. The cleansed sample was weighed using the analytical balance and the weight being recorded.

\section{Haematoxyllin-Eosin (HE) Staining}

Mammae glands were sliced, then made in paraffin blocks and cut thinly with $4 \mu \mathrm{m}$ thick, then stained with hematoxylin dye and followed by eosin, then mounted and covered with a glass deck. Qualitative observations were performed under a light microscope with $40 x$ magnification, whereas 
quantitative tests were used to calculate the number of lobolus cells using 3 different fields of view.

\section{Staining of Agyrophyllic Nucleolar Organizer Region (AgNOR)}

Histologic tissue preparate were prepared in the buffer then incubated in the autoclave. The preparate then stained with silver staining mixture, dehydrated with ethanol and affixed to the resin or synthesis medium. Observations were made by counting black dots converted to $\mathrm{mAgNOR}$ values as the average number of black dots on at least 100 cells.

\section{Data Analysis}

The results of uterine weight were analyzed by MS Office Excel 2010 in units of mg/100g BW. The statistical test was performed with SPSS version 17.0 in the Kolmogorov-Smirnov test to determine the normality of the data. Statistical significance test for normal distributed data is performed with one way ANOVA followed by post-hoc Tukey HSD test with $95 \%$ confidence level. The results of $\mathrm{H} \& \mathrm{E}$ and AgNOR staining were statistically analyzed by one-way ANOVA and post hoc Tukey HSD test at $95 \%$ confidence level.

\section{RESULTS AND DISCUSSION}

\section{Effect of EEPP in Increasing Uterus Weight of Ovariectomized Rat}

Examination of uterine weights was performed to determine the effect of EEPP on uterine animal weights (Table 1.)

Table 1 shows the differences in uterine weight between the baseline group of NOVX and OVX, indicating that the ovariectomy operation was successful. The ability of EEPP as phytoestrogen is shown from the comparison of uterine weight of the test group with the untreated group. From these results, EEPP has a tendency to increase uterine weight in female Sprague Dawley ovariectomized rats.
Table 1. Effect of EEPP on rat uterine weight.

\begin{tabular}{lc}
\hline \multicolumn{1}{c}{ Group } & $\begin{array}{c}\text { Uterine weight } \\
(\mathbf{m g} / \mathbf{1 0 0 g r} \mathbf{B W})\end{array}$ \\
\hline OVX Baseline & $56.67 \pm 29.14$ \\
NOVX Baseline & $398.22 \pm 98.64$ \\
EEPP $1000 \mathrm{mg} / \mathrm{kgBW}$ & $279.36 \pm 123.40$ \\
EEPP $500 \mathrm{mg} / \mathrm{kgBW}$ & $277.59 \pm 262.66$ \\
CMC-Na & $28.05 \pm 300.50$ \\
Estradiol & $142.15 \pm 289.15$ \\
Untreated & $36.89 \pm 160.99$ \\
\hline
\end{tabular}

Data analysis using one way ANOVA test followed by Tukey HSD test with 95\% confidence level.

Estrogen plays an important role in uterine development. At puberty the uterus has a high response to estrogen. The presence of estrogen stimulates the increase in water content in cells, DNA, RNA, protein synthesis, and activation of enzymes in the uterus. This event results in an increase in uterine weight due to the entry of water into the tissue of the uterus followed by cell proliferation and the accumulation of solids in the uterus (Turner and Bagnara, 1988). Further research suggests that in the uterus, the bond between estrogen and the ER $\alpha$ receptor causes proliferation of uterine cells, luminal epithelium and uterine estrogen receptor genes that impact on uterine weight increased (Frasor, et al., 2003).

\section{The Effect of Haematoxyllin and Eosin (H\&E) Staining}

Staining is done to see histologic images of breast cells from the test animals. The estrogenic effects of EEPP were seen from microscopic lobular images. Then the number of lobules is quantified by observing each preparate of three planes view. From Figure 1, it can be seen that the administration of EEPP concentration of $500 \mathrm{mg} / \mathrm{kgBW}$ was able to increase the number of lobular cells when compared with the OVX control group, but at a concentration of $1000 \mathrm{mg} / \mathrm{kgBW}$ was not able to increase the number of lobular cells compared with $500 \mathrm{mg} /$ 


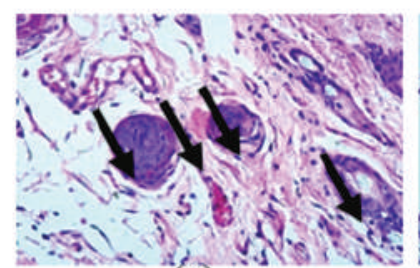

(a)

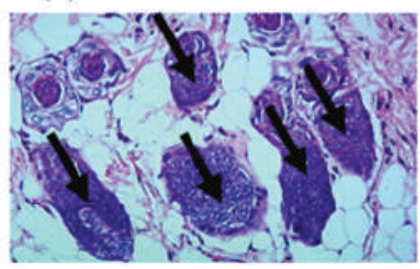

(e)

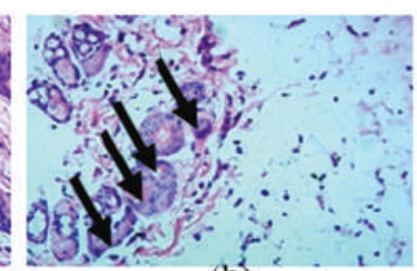

(b)

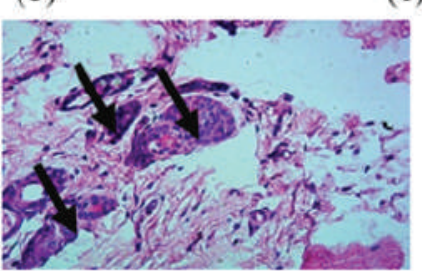

(f)

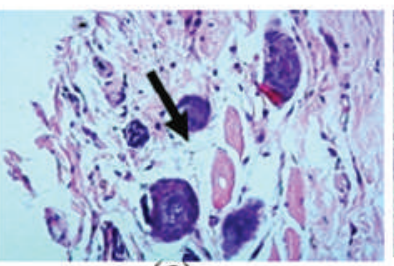

(c)

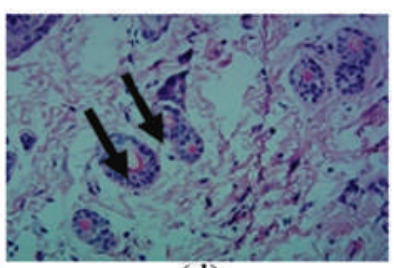

(d)

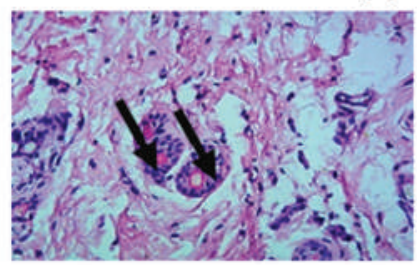

(g)

Figure 1. Histologic picture of rats mammae gland with HE painting after EEPP treatment. Mammae glands were observed with HE staining. (a) The baseline nonovariectomy group (NOVX), (b) the baseline ovariectomy group (OVX), (c) the OVX + CMC-Na group, (d) the OVX + estradiol group $2 \mu \mathrm{g} /$ day group, (e) the OVX + EEPP $500 \mathrm{mg} /$ $\mathrm{kgBW}$ group, (f) OVX + EEPP $1000 \mathrm{mg} / \mathrm{kgBW}$ group, and (g) OVX control group. Observations were performed under a light microscope with a magnification of 40x. The arrows show the lymph nodes of mammae gland. EEPP estrogenic effects are indicated by an increase in the number of lobules compared with the control group.

kgBW concentration. From these results, EEPP tends to increase the development of mammae gland by increasing breast lobule cells (Figure 2).

\section{Effect of EEPP on Agyrophyllic Nucleolar Organizer Region (AgNOR) Staining}

Staining AgNOR (Agryophilic Nucleolar Organizer Region) or silver staining is performed to determine the proliferative effect of EEPP on breast cells in ovariectomized rats. This method is able to show cell division by quantifying the Nucleolar Organizer Region (NOR) which indicates cell proliferation activity (Derenzini et al., 2003 ). The calculated number of black dots is quantified in $\mathrm{mAgNOR}$ by counting the total number of black dots on at least 100 cells then on average by dividing the total number of black dots. From the picture above, seen in the provision of EEPP concentration of $500 \mathrm{mg} / \mathrm{kgBW}$ can increase the number of black dots more than $1000 \mathrm{mg} / \mathrm{kgBB}$

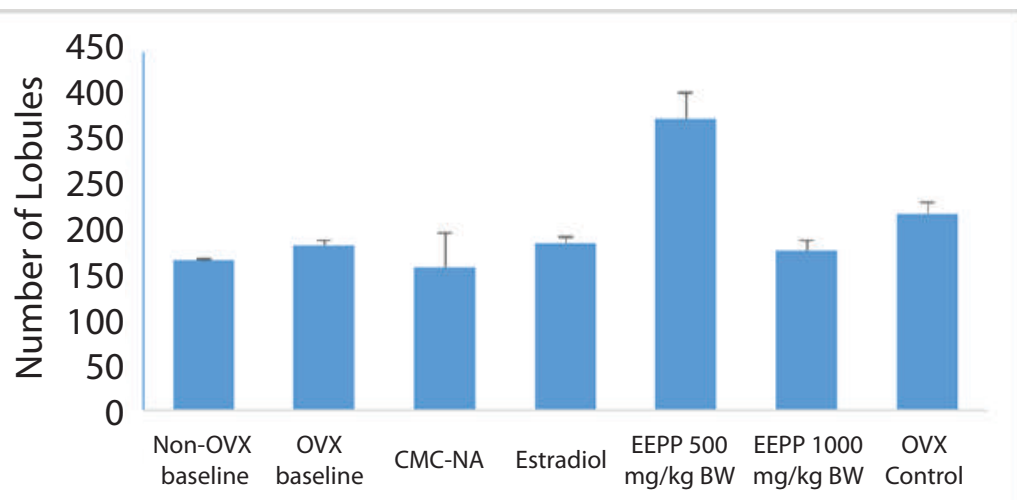

Test Groups
Figure 2. Number of lobules in the ovariectomized rats graph. Amount of lobules are quantified by observing the preparate in three different fields of view. The displayed image shows the mean \pm SE value of 3 experiments. Data analysis using one way ANOVA test followed by Tukey HSD test with $95 \%$ confidence level. 


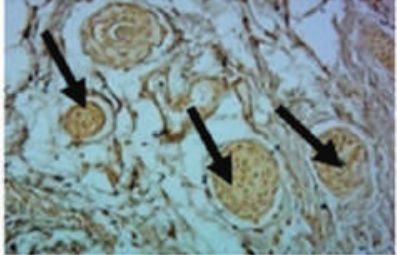

(a)

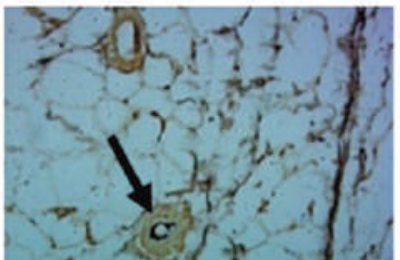

(b)

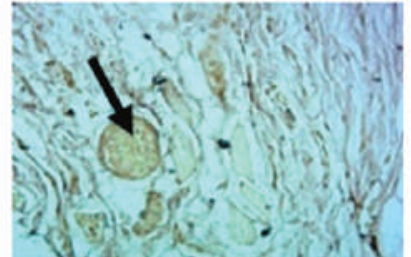

(c)

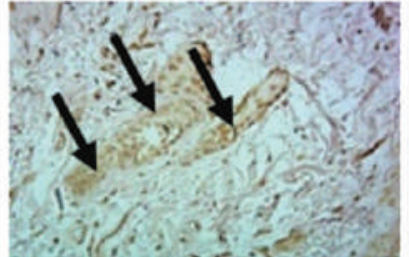

(d)

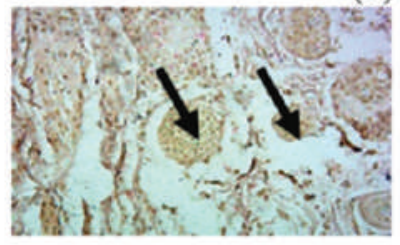

(e)

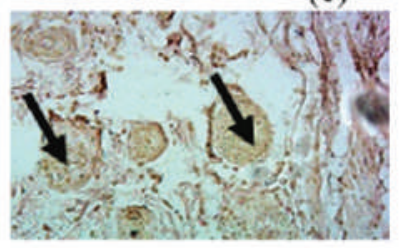

(f)

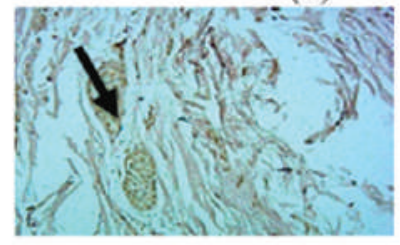

(g)

Figure 3. Histologic image of rats mammae gland with AgNOR staining after EEPP treatment. Mammae glands were observed with AgNOR staining. (a) The baseline nonovariectomy group (NOVX), (b) the baseline ovariectomy group (OVX), (c) the OVX + CMC-Na group, (d) the OVX + estradiol $2 \mu \mathrm{g} /$ day group, (e) the OVX + EEPP $500 \mathrm{mg} /$ kgBW group, (f) OVX + EEPP $1000 \mathrm{mg} / \mathrm{kgBW}$ group, and (g) OVX control group. Observations were performed under a light microscope with a magnification of 40x. The arrows show the lobule cells of the mammae glands. The estrogenic effects of EEPP are indicated by increase in the number of black dots compared with the control group.

concentration. From these results, EEPP tends to increase the development of mammae gland with the increased of breast cells proliferation (Figure 3, Figure 4).

\section{CONCLUSION}

Based on in vivo studies that have been done, it can be concluded that EEPP can be used as a source of phytoestrogens that have been prove to increase the uterine weight and increase the proliferation of mammae gland cells.

\section{ACKNOWLEDGEMENT}

The author would like to thank the DP2M DIKTI who has funded this research through PKM 2015 and Cancer Chemoprevention Research Center (CCRC) Faculty of Pharmacy UGM that supervise this study.

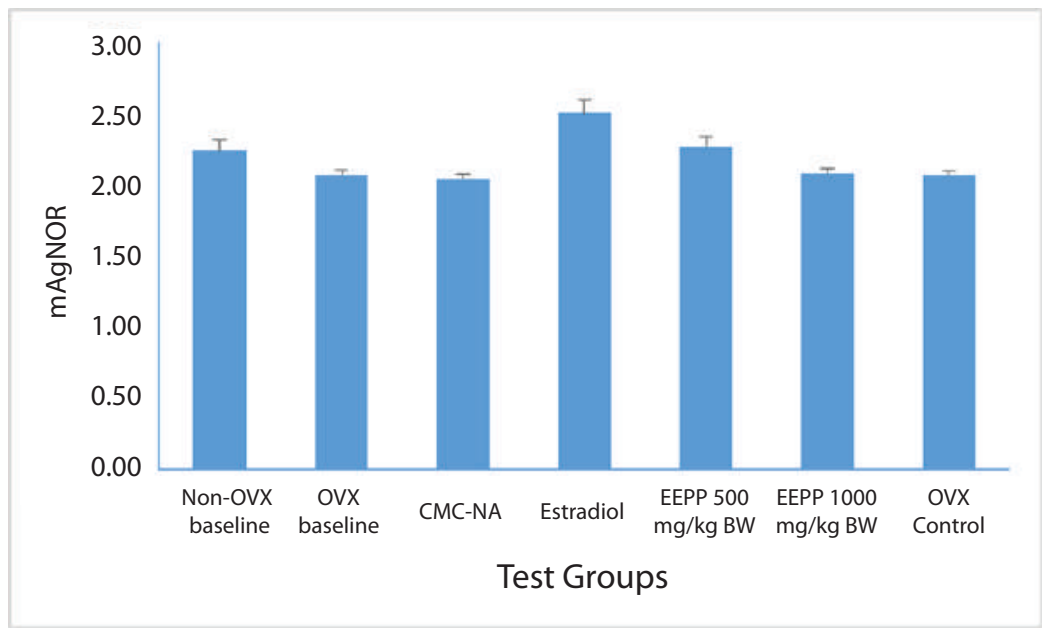

Figure 4. Graph of mAgNOR number in mammae cells of ovariectomized rats. The amount of the lobules are quantified by observing the preparate of five different fields of view. The displayed image shows the mean $\pm \mathrm{SE}$ value of 3 experiments. Data analysis using one way ANOVA test followed by Tukey HSD test with $95 \%$ confidence level. 


\section{REFERENCES}

Chlebowski, R.T., Lewis, H.K., Ross, L.P., Marcia, L.S., JoAnn, E.M., Margery, G., et al., 2009. Breast Cancer after Use of Estrogen plus Progestin in Postmenopausal Women, N. Engl. J. Med., 360(6), 573-587.

Frasor, J., Barnett, D.H., Danes, J.M., Hess, R., Parlow, A.F. and Katzenellenbogen, B.S., 2003, Response-Specific and Ligand Dose Dependent Modulation of Estrogen Reseptor (ER) Alpha Activity by ER Beta in the Uterus, Endocrinology, 144(7), 3159-3166.

Jordan, V., 2004. Selective Estrogen Receptor Modulation: Concept and Consequences in Cancer, Cancer Cel., 15, 207-213.

Maggiolini, M.A., Recchia, G., Bonofiglio, D., Catalano, S., Vivacqua, A., Carpino, A., et al., 2005, The Red Wine Phenolics Piceatannol and Myricetin Act as Agonists for Estrogen Receptor in Human Breast Cancer Cells, J. Clin. Mol. Endocrinol., 35, 268-281.

Mendelsohn, M.E. and Karas, R.H., 2010, Rapid Progress for Non-nuclear Estrogen Receptor Signaling. J. Clin. Invest., 120(7), 2277-2279.
Oh, S.M., Kim, Y.P. and Chung, K.H., 2006. Biphasic Effects of Kaempferol on the Estrogenicity in Human Breast Cancer Cells, Arch. Pharm. Res., 29(5), 354-362.

Pratama, N.R., Gilang, Y., Riata, R., Hermawan, A., Ikawati, M. and Meiyanto, E. , 2011, Banana Peels (Musa paradisiaca L.) Extract as Phytoestrogen on Ovariectomized Mice Mammary Gland Development by Inducing c-Myc Expression. Indones. J. Cancer Chemoprevent., 2(1), 151159.

Rivera-Pastrana, D.M., Yahia, E.M. and GonzálezAguilar, G.A., 2010, Phenolic and Carotenoid Profiles of Papaya Fruit (Carica papaya L.) and their Contents Under Low Temperature Storage. J. Sci. Food Agric., 14(90), 2358-2365.

Trivedi, R., Kumar, S., Kumar, A., Siddiqui, J.A., Swarnkar, G., Gupta, V., et al., 2008, Kaempferol has Osteogenic Effect in Ovariectomized Adult Sprague-Dawley Rats, Mol. Cell. Endrocinol., 289(1), 85-93.

Turner, C.D. and Bagnara, J.T., 1988, Endokrinologi Umum, Surabaya: Airlangga University Press.

Yildiz, F., 2005, Phytoestrogens in Functional Foods, Boca Raton: Taylor and Francis Ltd. 